\title{
Instability of municipal solid waste along the constant deviatoric stress path and its engineering significance
}

\author{
HAN KE*, PENGCHENG MA $\uparrow$, YUNMIN CHEN*, DING DONG $\ddagger$, SHIYU ZHAO $\dagger$, YIQING YANG§ and \\ CHIDOCHASHE CLEMENCY NHEMA $\dagger$
}

\begin{abstract}
To investigate the instability behaviours of municipal solid waste under the reduction of effective means stress, consolidated undrained (CU), constant shear drained (CSD) and constant shear undrained (CSU) tests were conducted on artificial waste specimens. In CU tests, the effective stress paths were modified by considering the particle compressibility, and the waste specimens did not exhibit pre-failure softening behaviours. Instability of the waste was observed in CSD tests, but was not observed in CSU tests. When the waste specimens became unstable, the axial strains increased rapidly and the volume was severely dilated. Softening of the waste specimens, manifested in the inability to maintain constant deviatoric stresses, was also observed. For waste specimens with similar void ratios, the instability points were located around an instability line (IL), and the slope of the IL decreased with an increase in the void ratio. Some factors, including the stress path and deformation characteristic of waste, may lead to the instability of waste specimens in CSD tests by influencing the effects of reinforcements. In engineered landfills, high pore pressure is often generated in waste mass and then leads to the obvious reduction of the effective stress of waste; thus, waste instability needs to be considered in the safety evaluation of waste slopes.
\end{abstract}

KEYWORDS: high pore pressure; instability; municipal solid waste (MSW); safety evaluation; waste, waste management \& contaminated land

\section{INTRODUCTION}

Landfilling is one of the main methods for disposing of municipal solid waste (MSW, hereafter referred to as 'waste') worldwide. Waste sliding is a common disaster in landfills, which can severely affect their normal operation and may even result in the loss of properties and lives (e.g. Giraldo et al., 2002; Merry et al., 2005; Athanasopoulos et al., 2013; Zhan et al., 2018). The causes of waste sliding are varied. By analysing several sliding cases, Koerner \& Soong (2000) concluded that the pressure of leachate and landfill gas (i.e. pore pressure) is a vitally important cause of sliding. Furthermore, Ma et al. (2019) found a direct correlation between high pore pressure and the sliding surface in a landfill in China through drilling and geophysical investigations. Waste can generate a large amount of leachate and landfill gas during biodegradation. If the collection system for these products is insufficient, high pore pressure in the waste mass may arise. In addition, high pore pressure can result from other factors, such as rainwater infiltration during heavy rains and aggressive leachate injection (Koerner \&

Manuscript received 19 October 2020; revised manuscript accepted 7 May 2021. Published online ahead of print 20 September 2021. Discussion on this paper closes on 1 March 2023, for further details see p. ii.

Published with permission by the ICE under the CC-BY 4.0 license. (http://creativecommons.org/licenses/by/4.0/)

* MOE Key Laboratory of Soft Soils and Geoenvironmental Engineering, Center for Hypergravity Experimental and Interdisciplinary Research, Institute of Geotechnical Engineering, Zhejiang University, Hangzhou, P. R. China.

$\dagger$ MOE Key Laboratory of Soft Soils and Geoenvironmental Engineering, Institute of Geotechnical Engineering, Zhejiang University, Hangzhou, P. R. China.

* Shanghai Municipal Engineering Design Institute, Shanghai, P. R. China.

$\S$ Guangzhou Environmental Protection Investment Group Co. Ltd, Guangzhou, P. R. China.
Soong, 2000; Blight, 2008; Feng et al., 2018). During the dumping process, waste mainly sustains the increase in external load. However, for an existing waste mass that has been dumped, considering the increase in pore pressure, the reduction of effective stress plays a dominant role in the safety of the waste slope, especially when the variation in the external load is not significant. Therefore, the mechanical responses of waste under reduced effective stress should be noted in the evaluation of stability.

The situation in which the external load does not change significantly and the pore pressure keeps increasing can be represented by an idealised stress path with constant deviatoric stress $\left(q=\sigma_{1}^{\prime}-\sigma_{3}^{\prime}\right)$ and decreasing effective mean stress $\left(p^{\prime}=\left(\sigma_{1}^{\prime}+2 \sigma_{3}^{\prime}\right) / 3\right)$ in the triaxial condition, which is the so-called constant shear drained (CSD) test. For soil slopes, there are some failure cases that result from an increase in pore pressure rather than external load (Turner \& Pidgeon, 1997; Chu et al., 2003). To investigate the failure mechanism in this condition, many researchers have conducted triaxial tests with similar stress paths to the CSD test on soil specimens and have observed the instability of cohesionless soils before the failure state (e.g. Lade et al., 1988; Lade \& Pradel, 1990; Anderson \& Riemer, 1995; Chu et al., 2003; Dong et al., 2017). Instability is defined as when soil cannot sustain the external load and thus rapidly yields to large plastic deformation (Lade, 1993; Chu et al., 2003). In strict CSD tests, the instability of loose sand (i.e. contractive sand) and dense sand (i.e. dilative sand) has been observed when the stress ratios $\left(\eta=p^{\prime} / q\right)$ were smaller than the failure stress ratios (i.e. before the failure state (Chu et al., 2003; Dong et al., 2017)). However, when specimens of dense sand were sheared with constant deviatoric stress in the undrained condition (constant shear undrained, CSU), instability did not occur (Chu et al., 2015). The unstable behaviours of sand specimens included a rapid increase in axial strains, dramatic changes in volume strains, softening and even physical collapse. In brief, the instability of sands creates large deformation before the final failure; hence, it 
reveals a valuable mechanism of slope sliding under the reduction of $p^{\prime}$.

In consolidated undrained (CU) tests, loose sand specimens can exhibit softening behaviours before the failure state, and these phenomena are similar to instability. Lade (1993) defined the instability line in loose sand by connecting the softening points of effective stress paths in CU tests. Chu \& Leong (2001) also pointed out that the mechanism of pre-failure softening is the same as that of instability in CSD tests by analysing test data.

At present, the understanding of the mechanical characteristics of waste is relatively limited because most of the data were obtained from conventional triaxial compression tests (such as consolidated drained and undrained tests) or direct shear tests, in which waste behaved as a continuous hardening material. In other words, the deviatoric stresses continued to increase and the critical states were still not reached even under very high strain levels (Machado et al., 2002; Karimpour-Fard et al., 2011; Ke et al., 2019). Thus, using these tests, the strength parameters of waste had to be related to the strain levels (Dixon \& Jones, 2005). The continuous hardening of waste is believed mainly to be attributable to the hardening of the reinforcement components in waste, such as plastics, rubbers, fabrics and similar sheet materials (Bray et al., 2009). The limitations of current understanding of the mechanical responses of waste mainly lie in two aspects. Considering the aspect of research integrity, the mechanical responses of waste along other stress paths that exist in actual engineering conditions but cannot be reflected by conventional triaxial tests (e.g. CSD path) are still unknown. Considering the aspect of engineering application, the continuous hardening indicates that waste is difficult to damage, which does not seem to explain appropriately the frequent waste sliding in landfills worldwide.

In the present study, a series instability tests were conducted on artificial waste specimens to explore their mechanical responses with the reduction of effective mean stress. In addition, $\mathrm{CU}$ tests, which are conventional triaxial tests with reduction of $p^{\prime}$, were also conducted. Because the particle compressibility of waste cannot be ignored (Shariatmadari et al., 2009; Machado et al., 2017), the compression characteristics of the waste particles were investigated through an isotropic compression (IC) test and the effective stress paths in CU tests were modified accordingly. The instability tests included a drained constant $p^{\prime}$ shearing stage and a CSD or CSU stage. The instability of waste specimens, manifested in the rapid increase in axial strain and the severe dilatancy of specimen volume, was observed in the instability tests with a CSD stage. However, the specimens were stable in the CU tests and instability test with a CSU stage. Then, some factors regarding stress and deformation of waste which may lead to waste instability in CSD tests were discussed from the perspective of the effects of reinforcement components. Finally, the engineering significance of the waste instability was discussed in combination with a sliding case of waste mass.

\section{MATERIALS AND METHODS \\ Test apparatus and specimens}

All the tests were conducted using an advanced triaxial testing system that can precisely control the stress path. Two digital pressure volume controllers (DPVCs) were used to control the confining pressure in the chamber and the back-pressure in the specimen. The axial stress was controlled by a servo motor and a force sensor. Considering the particle compressibility, the volume change of waste specimens cannot only be reflected by the amount of water drainage; hence, the overall volume change, which can be measured by the DPVC connecting to the chamber, was also recorded. Then, the difference between the overall volume change and water drainage was the volume change in waste particles (refer to Shariatmadari et al. (2009)). In addition, to avoid the measuring error induced by the deformation of the chamber wall, a double-layered pressure chamber was applied. During the tests, the pressure in the outer chamber was controlled by a gas pressure controller and maintained to be consistent with the pressure in the inner chamber. Thus, the wall of the inner chamber did not deform because it was in a state of force balance.

The diameter and height of the specimens were $101 \mathrm{~mm}$ and $200 \mathrm{~mm}$, respectively. To improve the homogeneity of the specimens and the repeatability of the tests, artificial waste, rather than natural waste, was applied in this study. The two compositions of the artificial waste used in the tests are shown in Table 1. Composition A refers to the waste composition applied in the triaxial tests of Feng (2005). In contrast to typical waste composition in developing countries, the content of food components is relatively low and the content of sand is much higher. On the one hand, a low content of foods can reduce the difficulties in creating homogeneity of specimens to ensure the comparability of test results of different specimens. On the other hand, a high content of sand can increase the waste stiffness so that the special stress paths in this study can be controlled more accurately by the apparatus. On the basis of composition A, in composition B the content of food components was reduced to zero and the contents of the other components were scaled up. By comparing the test results of composition $\mathrm{A}$ and $\mathrm{B}$, the influences of biodegradation on the mechanical responses of the waste could be roughly approximated. Note that other changes in the process of biodegradation - such as the strength reduction of reinforcements, saturation variation due to gas generation and residue of lignin in organic matter - cannot be reflected in this study. In natural waste, each component is made up of a variety of materials. However, in the artificial waste of this study, to avoid the uncontrolled errors caused by material variances, only one or

Table 1. Composition of the artificial waste tested (dry basis)

\begin{tabular}{|c|c|c|c|c|c|c|c|c|c|c|}
\hline \multicolumn{2}{|l|}{ Component } & Food & Paper & Plastic & Rubber & Fabric & Wood & Soil & Glass & Metal \\
\hline \multicolumn{2}{|l|}{ Materials } & $\begin{array}{l}\text { Cabbage } \\
\text { and } \\
\text { chicken* }\end{array}$ & Tissue & $\begin{array}{l}\text { PVC } \\
\text { slice† }\end{array}$ & $\begin{array}{c}\text { Latex } \\
\text { membranet }\end{array}$ & $\begin{array}{l}\text { Strip of } \\
\text { cotton } \\
\text { cloth }\end{array}$ & $\begin{array}{l}\text { Wood } \\
\text { chip }\end{array}$ & $\begin{array}{l}\text { Clayey } \\
\text { sand }\end{array}$ & $\begin{array}{c}\text { Glass } \\
\text { fragment }\end{array}$ & $\begin{array}{c}\text { Scrap } \\
\text { iron }\end{array}$ \\
\hline Mass proportion: $\%$ & $\begin{array}{l}\text { A } \\
\text { B }\end{array}$ & $\begin{array}{l}17 \cdot 5 \\
0\end{array}$ & $\begin{array}{l}4 \cdot 2 \\
5 \cdot 1\end{array}$ & $\begin{array}{l}6 \cdot 7 \\
8 \cdot 1\end{array}$ & $\begin{array}{l}0 \cdot 6 \\
0 \cdot 7\end{array}$ & $\begin{array}{l}7 \cdot 6 \\
9 \cdot 2\end{array}$ & $\begin{array}{l}4 \cdot 5 \\
5 \cdot 5\end{array}$ & $\begin{array}{l}57 \cdot 2 \\
69 \cdot 3\end{array}$ & $\begin{array}{l}0 \cdot 5 \\
0 \cdot 6\end{array}$ & $\begin{array}{l}1 \cdot 2 \\
1 \cdot 5\end{array}$ \\
\hline
\end{tabular}

*The ratio of dry weight of cabbage to chicken in the food component was 2:3.

$\dagger$ The thickness of the polyvinyl chloride (PVC) slice is $0 \cdot 1 \mathrm{~mm}$.

$\$$ The thickness of the latex membrane is $0.3 \mathrm{~mm}$. 
two materials were selected for each component. The specific weight of the tested waste of composition A and B was $2 \cdot 14$ and $2 \cdot 37$, respectively. In addition, the particle sizes of all components were controlled to be less than one-fifth (for reinforcement components) to one-tenth (for other components) of the specimen diameter to avoid the influence of particle size on the results of the triaxial tests.

\section{Test arrangement}

Three CU tests and ten instability tests were conducted in this study. Before the tests, the waste specimens were vacuum saturated for $24 \mathrm{~h}$ and the measured $B$ value was larger than 0.95 . The back-pressure saturation was not adopted because the waste specimens easily produced large deformation during the increase in the back-pressure.

The specimens of the CU tests were made up of the waste of composition A. After saturation, the waste specimens were isotropically consolidated with effective confining pressures of 100,300 and $400 \mathrm{kPa}$. Then, the specimens were sheared with constant confining pressures under undrained conditions until the axial strain reached $30 \%$. The details of the CU tests conducted in this study are shown in Table 2.

Table 2. List of consolidated undrained (CU) tests conducted

\begin{tabular}{l|c|c}
\hline Test no. & $\begin{array}{c}\text { Effective confining } \\
\text { pressure, } \sigma_{3}^{\prime}: \mathrm{kPa}\end{array}$ & $\begin{array}{c}\text { Void ratio after } \\
\text { consolidation, } e_{\mathrm{c}}\end{array}$ \\
\hline ACU01 & 100 & $1 \cdot 48$ \\
ACU02 & 300 & $1 \cdot 21$ \\
ACU03 & 400 & $1 \cdot 12$ \\
\hline
\end{tabular}

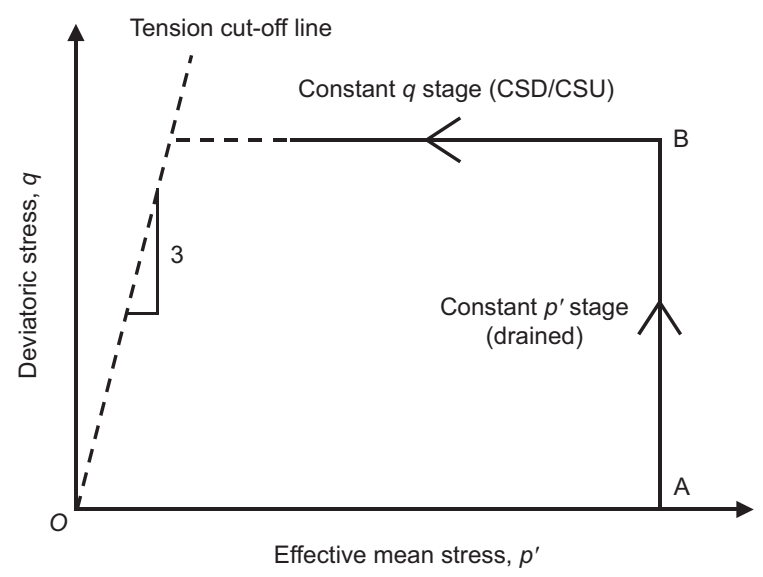

Fig. 1. Schematic diagram of the stress path of the instability test
Particle compressibility can influence the effective stress in soil (Skempton, 1960). Therefore, to modify the results of CU tests, an IC test was conducted, in which a waste specimen was successively loaded to 100, 200, 300 and $400 \mathrm{kPa}$. Each stress level was maintained for $24 \mathrm{~h}$ and the overall and particle volume changes were recorded and calculated.

A schematic diagram of the stress path in the instability tests is shown in Fig. 1. The tests included two stages after the process of saturation and consolidation. The first stage was the constant $p^{\prime}$ stage - that is, the effective mean stress remained constant and the deviatoric stress increased under drained conditions. This stage ended when the stress states of the specimens reached the given stress states. The second stage was the CSD or CSU stage, in which the stress-strain behaviours of the waste need to be mainly focused. The reduction rate of $p^{\prime}$ in the CSD stage (or $p$ in the CSU stage) was selected as $0.5 \mathrm{kPa} / \mathrm{min}$. It should be noted that the critical state of the waste was not reached in the tests; therefore, the constant $q$ stages ended when the specimens collapsed from instability or the stress paths were close to the tension cut-off line $(\mathrm{H}: \mathrm{V}=1: 3)$. In the tests, the four specimens in group A (A01-A04) were made up of the waste of composition $\mathrm{A}$ and the six specimens in group $\mathrm{B}$ (B01-B06) were made up of the waste of composition B. The other details of the instability tests are shown in Table 3.

\section{TEST RESULTS}

Results of the CU tests considering particle compressibility

Considering particle compressibility, the effective stress principle of soil needs to be modified as follows (Skempton, 1960)

$$
\sigma^{\prime}=\sigma-A u=\sigma-\frac{C_{\mathrm{s}}}{C} u
$$

where $A$ is the pore pressure reduction factor; $C_{\mathrm{s}}$ is particle compressibility; and $C$ is the overall compressibility of soil. $C_{\mathrm{s}}$ and $C$ are defined as

$$
\begin{aligned}
& C_{\mathrm{s}}=\left(\Delta V_{\mathrm{p}} / V_{\mathrm{p}}\right) / \Delta u \\
& C=(\Delta V / V) / \Delta p^{\prime}
\end{aligned}
$$

where $\Delta V_{\mathrm{p}}$ and $\Delta V$ is the particle volume change and overall volume change, respectively; $\Delta u$ and $\Delta p^{\prime}$ is the change of pore pressure and effective mean stress, respectively. Considering $u$ and $p^{\prime}$ are both neutral stress and may have similar effects on the compression of waste particles, in this study, $C_{\mathrm{s}}$ was calculated as

$$
C_{\mathrm{s}}=\left(\Delta V_{\mathrm{p}} / V_{\mathrm{p}}\right) / \Delta p^{\prime}
$$

Table 3. List of instability tests conducted

\begin{tabular}{l|c|c|l|r|r}
\hline $\begin{array}{l}\text { Test } \\
\text { no. }\end{array}$ & $\begin{array}{c}\text { Void ratio after } \\
\text { consolidation, } e_{\mathrm{c}}\end{array}$ & $\begin{array}{c}\text { Deviatoric stress in constant } q \\
\text { path: kPa }\end{array}$ & CSD/CSU & $\begin{array}{c}q / p^{\prime} \text { at instability } \\
\text { point, } \eta_{\mathrm{I}}\end{array}$ & $\begin{array}{c}\text { Void ratio at instability } \\
\text { point, } e_{\mathrm{I}}\end{array}$ \\
\hline A01 & 1.49 & 100 & CSU & N/A & N/A \\
A02 & 1.22 & 200 & CSD & 1.65 & 1.20 \\
A03 & 1.38 & 150 & CSD & 1.36 & 1.35 \\
A04 & 1.51 & 100 & CSD & 1.33 & 1.48 \\
B01 & 1.07 & 250 & CSD & 2.50 & 1.05 \\
B02 & 1.02 & 200 & CSD & 2.56 & 1.01 \\
B03 & 1.55 & 125 & CSD & 1.96 & 1.52 \\
B04 & 1.62 & 100 & CSD & 1.97 & 1.59 \\
B05 & 1.54 & 75 & 1.79 & 1.53 \\
B06 & 1.89 & 50 & CSD & 1.87 \\
\hline
\end{tabular}


A similar idea was also proposed by Machado et al. (2017).

The $C_{\mathrm{s}}$ and $C$ values of the waste of composition A obtained from the IC test are plotted in Fig. 2. With the increase in $p^{\prime}, C_{\mathrm{s}}$ and $C$ decreased, indicating the compressibility of the waste particles and the whole specimen were inversely proportional to $p^{\prime}$. Their relationships can be appropriately fitted by the equations proposed by Shariatmadari et al. (2009)

$$
C\left(\text { or } C_{\mathrm{s}}\right)=\frac{p^{\lambda}-1}{p^{\lambda+1}}
$$

The value of parameter of $\lambda$ for $C$ and $C_{\mathrm{s}}$ is $0 \cdot 10$ and 0.0078 , respectively. As shown in Fig. 2(b), the pore pressure reduction factor $A$ is close to 0.9 and decreases slightly with $p^{\prime}$.

Overall, the particle compressibility of the tested waste of composition A was not obvious, compared with the waste tested by Powrie et al. (1999) and Shariatmadari et al. (2009).

The effective stress paths of the waste specimens in the CU tests are shown in Fig. 3(a). For the sake of comparison, the effective stress paths of the loose sand in the CU tests conducted by Chu et al. (2003) are also plotted in Fig. 3(b). It was found that the loose sand specimens first hardened and then softened during undrained shearing. By connecting the peak points of the effective stress paths, an instability line (IL) can be determined. After the softening points, the stress states finally reached the critical state line (CSL). However, the effective stress paths of the waste specimens were different. As shown in Fig. 3(a), the value of $q$ of the waste specimens kept increasing without any evidence of pre-failure softening. Without modification, the effective stress paths can approach the tension cut-off line at high axial strain level. As mentioned above, this phenomenon is in clear contradiction to the frequent waste sliding in landfills.

The effective stress paths modified considering particle compressibility are drawn by dotted lines in Fig. 3(a). Through modification, $p^{\prime}$ increased at the same $q$ value, meaning that the stress ratio $\left(\eta=q / p^{\prime}\right)$ decreased. With the increase in volume compression of particles, $\eta$ dropped more obviously. For the tested waste, the modified values of $\eta$ were still over $2 \cdot 1$ at the axial strain of $30 \%$, which is larger than the unstable stress ratios in CSD tests of the specimens of group A shown in the following sections. In addition, the modification did not change the hardening tendencies of the waste specimens. Thus, the above contradiction may not be explained by considering only particle compression.

\section{Results of the instability tests with a CSD stage}

As a representative of group A, the mechanical responses of the waste specimen in test A02 are presented in Fig. 4. Points $\mathrm{A}$ and $\mathrm{B}$ represent the starting points of the constant $p^{\prime}$

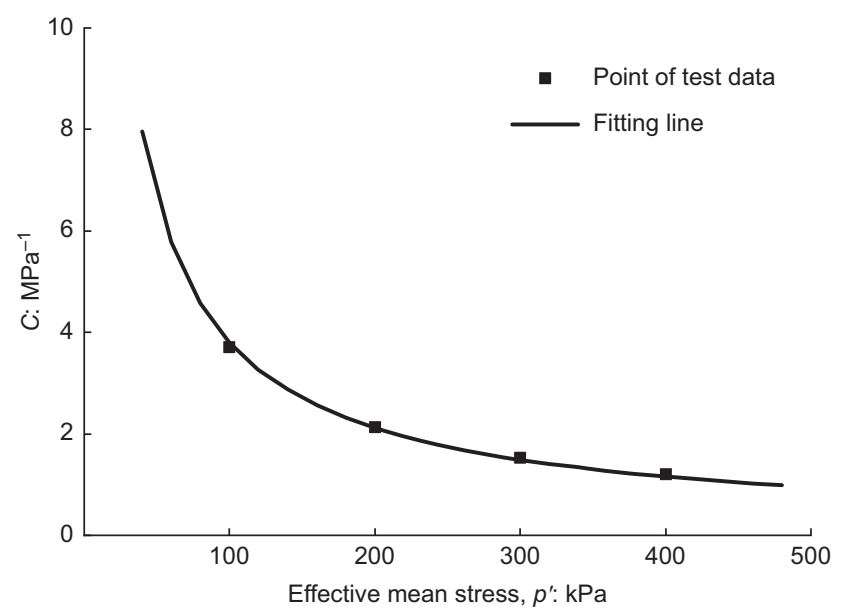

(a)

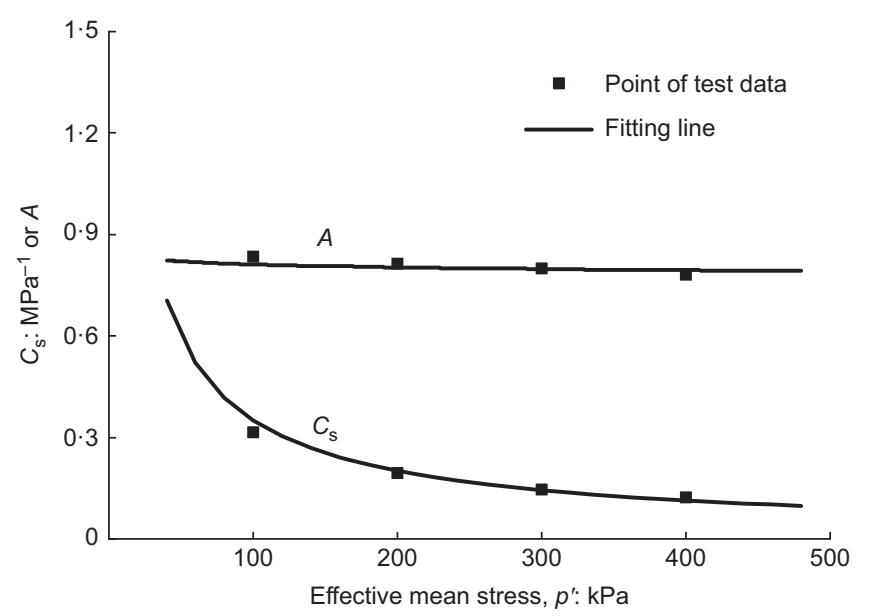

(b)

Fig. 2. Compressibility of the waste of composition A: (a) overall compressibility; (b) particle compressibility, and pore pressure reduction factor plotted against effective mean stress curves

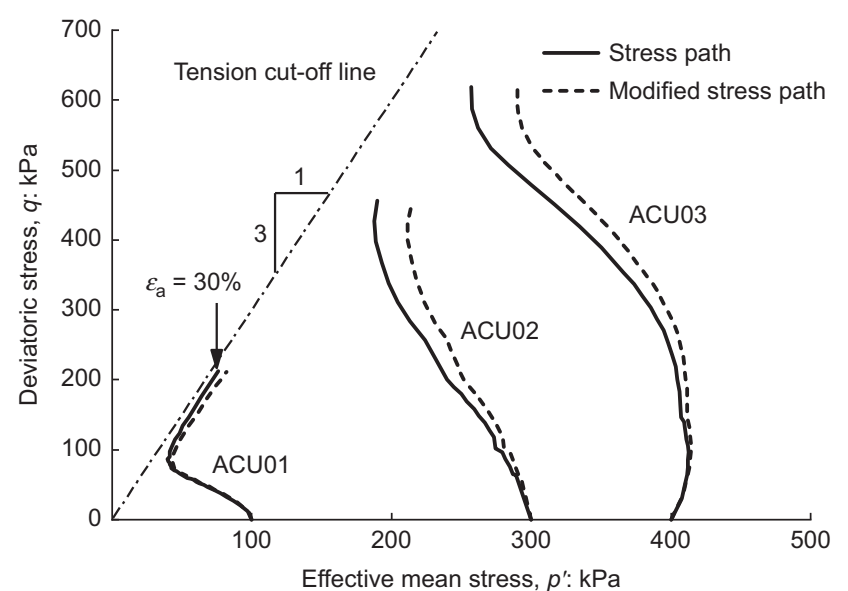

(a)

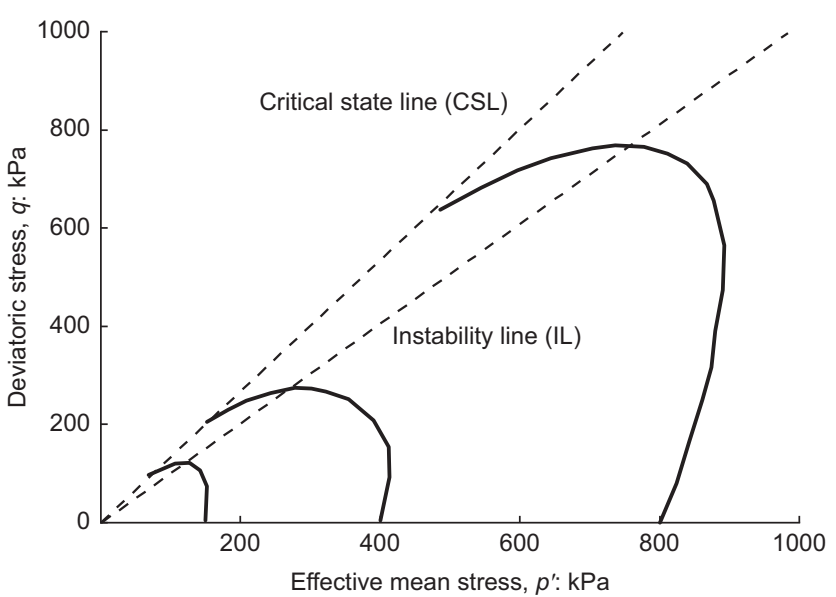

(b)

Fig. 3. Effective stress paths of (a) the artificial waste and (b) the loose sand (after Chu et al., 2003) in the CU tests 


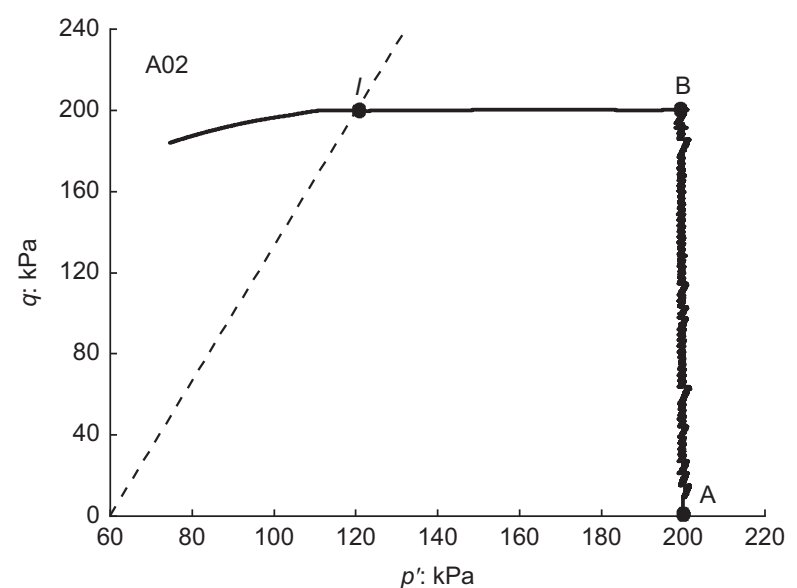

(a)

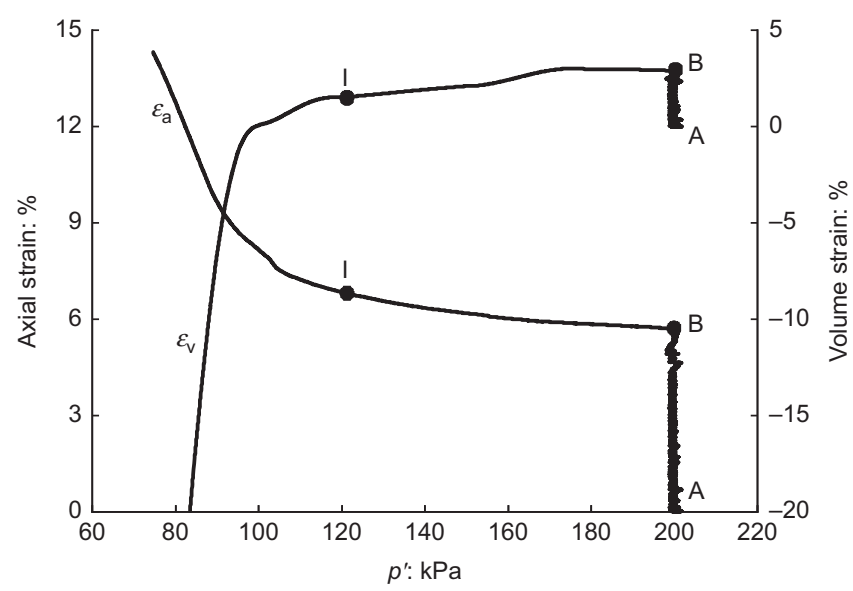

(c)

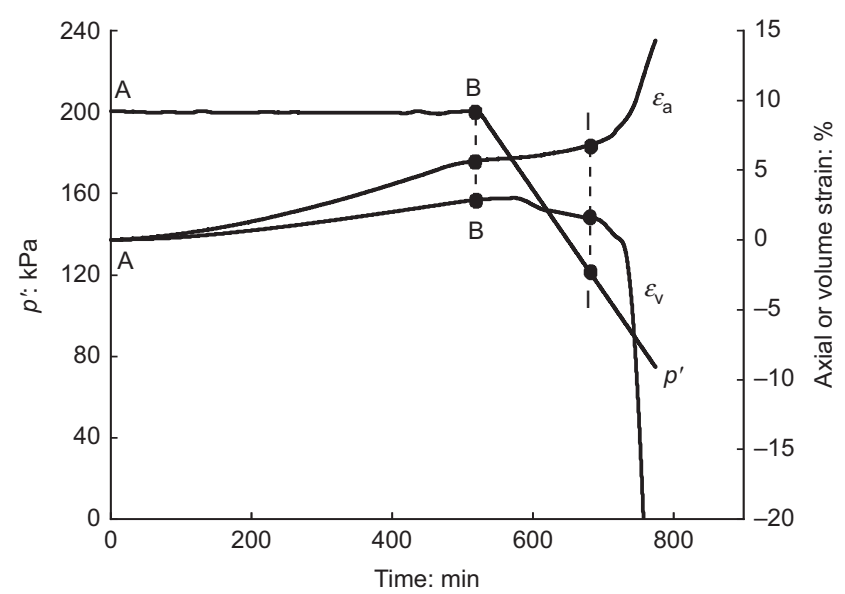

(b)

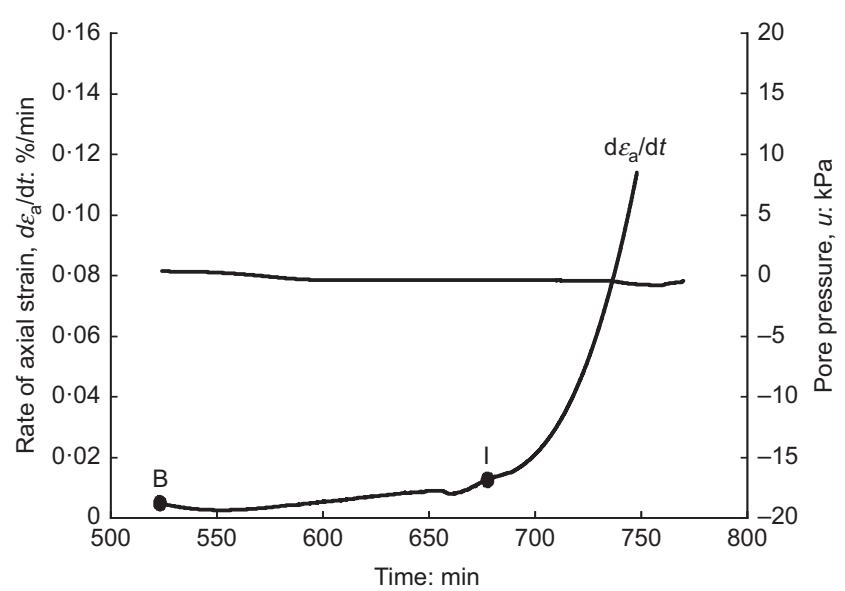

(d)

Fig. 4. Unstable behaviours of test A02: (a) effective stress path; (b) effective mean stress, axial strain and volume strain plotted against time curves; (c) axial and volume strain plotted against effective mean stress curves; and (d) rate of axial strain and pore pressure plotted against time curves

and constant $q$ stages, respectively, which correspond to the stress path shown in Fig. 1. As illustrated in Fig. 4(a), the stress path of the constant $p^{\prime}$ and constant $q$ stages was controlled well by the triaxial apparatus. The constant $q$ stage of A02 was in the drained condition (i.e. CSD); hence, the pore pressure did not change significantly in the test (see Fig. 4(d)) and effective stress modification was not needed.

In the constant $q$ stage, the axial strain increased slowly and the volume dilated slightly from point B to I; however, after point I, the axial strain increased rapidly and the volume was severely dilated. This means that the waste specimen in test A02 became unstable after the stress path reached point I, and correspondingly, point I was regarded as the instability point. In addition, the specimen softened in the unstable state, which was manifested in the inability to maintain a constant $q$ path. As shown in Fig. 4(d), the rate of axial strain was relatively small from point B to I, but increased at an accelerating rate after point $\mathrm{I}$, indicating that the instability became increasingly serious with the continuous reduction of $p^{\prime}$. Later in the constant $q$ stage, the axial and volume strain exhibited drastic changes in a short time, meaning that the waste specimen had physically collapsed. During the instability process, the non-homogeneous deformation and shear band of the waste specimens were not observed. This is consistent with the deformation modes of the sand specimens in their unstable states (Lade et al., 1988; Chu et al., 1992; Chu \& Leong, 2001).

Yielding is one of the necessary conditions of instability. In the constant $p^{\prime}$ stage, the waste specimen was in the plastic state; hence, point B was located on the yield surface. Then, the test entered the constant $q$ stage. From point B to I, the specimen was in an elastic state because the stress path was inside the yield surface in this process (Chu et al., 2003). Based on the elastic constitutive relation, the reduction of $p^{\prime}$ will induce a slight volume dilation in the elastic state, which can explain the test phenomena in this study. Point I is the intersection between the constant $q$ stress path and the yield surface, that is, the yield point. After point I, the waste specimen entered the plastic state; then, a large plastic deformation may develop and instability may occur.

Figure 5 presents the results of test B04. Unstable behaviours that were similar to those in test A02 can also be observed after the instability point. The specimen also collapsed at the later stage of the test. Nevertheless, the axial strain and axial strain rate of the specimen in test B04 were obviously smaller than those of the specimen in test A02. This may be a result of the difference in the proportions of the reinforcement components in compositions A and B. As shown in Table 1, composition A has a higher content of the reinforcement components; thus, in test B04, the restraint effect of the reinforcement components on the specimen deformation in an unstable state may be stronger. However, the final collapse of the specimen in test B04 also indicated that a higher content of reinforcement components may not be able to inhibit the instability development fundamentally.

The instability stress ratios $\left(\eta_{\mathrm{I}}=q_{\mathrm{I}} / p_{\mathrm{I}}^{\prime}\right)$ and the void ratios at the instability points $\left(e_{\mathrm{I}}\right)$ of all the tests are summarised in Table 3. 


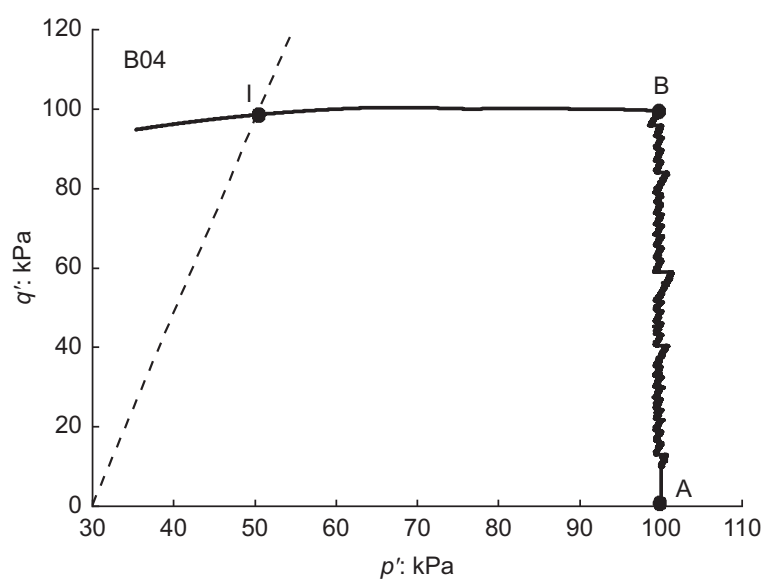

(a)

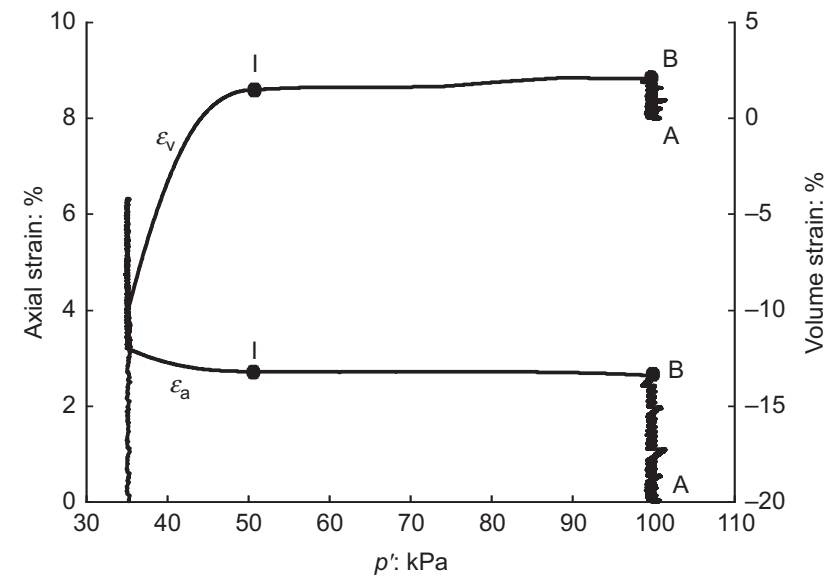

(c)

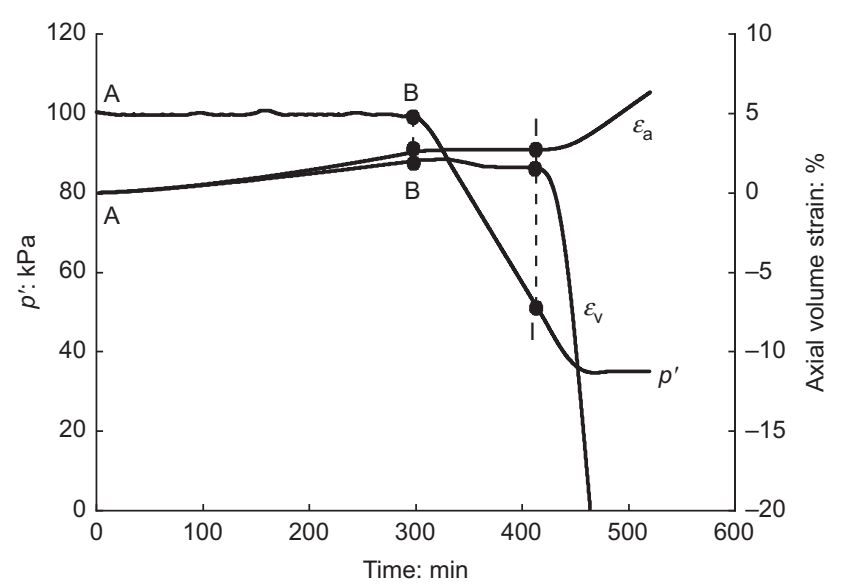

(b)

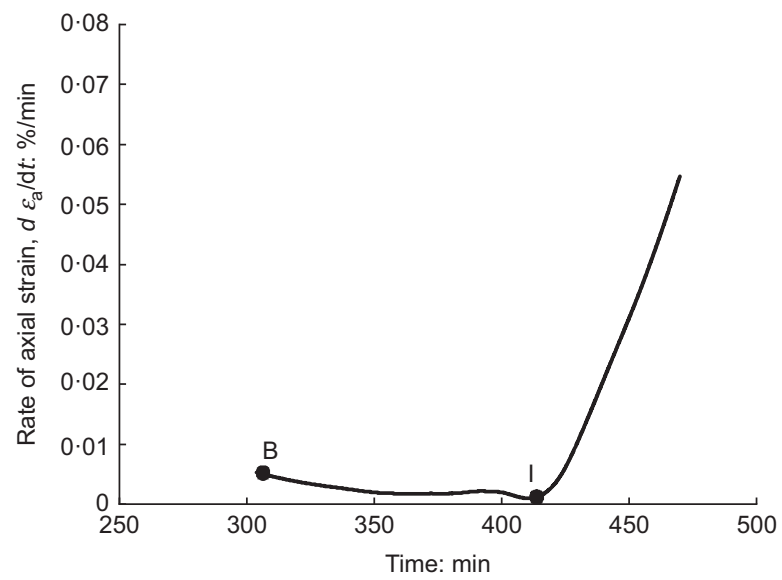

(d)

Fig. 5. Unstable behaviours of test B04: (a) effective stress path; (b) effective mean stress, axial strain and volume strain plotted against time curves; (c) axial and volume strain plotted against effective mean stress curves; and (d) rate of axial strain plotted against time curve

\section{Results of the instability test with a CSU stage}

The constant $q$ stage of test A01 was carried out under undrained conditions (i.e. CSU); hence, total mean stress rather than effective mean stress was controlled in it. As shown in Fig. 6, the axial strain did not increase rapidly with the reduction of $p$, indicating that the specimen did not exhibit obvious unstable behaviours. Because the volume dilatancy cannot be accommodated in an undrained condition, negative pore pressure developed. As a result, the effective mean stress did not decrease continuously as it did in CSD tests. Then, the development of plastic deformation may not be fierce and the instability of the waste specimen may be inhibited. A similar phenomenon was also observed in undrained constant $q$ tests of dilative sand, which was attributed to the development of negative pore pressure by Chu et al. (2015).

\section{Instability lines}

The instability points obtained from tests B01-B05 are plotted in Fig. 7. In the meridian plane, by connecting the instability points of the specimens with similar $e_{\mathrm{I}}$ (e.g. B01 and B02; B03, B04 and B05), an IL that goes through the original point can be obtained approximately, indicating that waste with similar density had a similar $\eta_{\mathrm{I}}$. In addition, it was found that the value of $e_{\mathrm{I}}$ was proportional to the value of $\eta_{\mathrm{I}}$. These results are similar to the results of the sand instability tests. The data points of $\left(e_{\mathrm{I}}, \eta_{\mathrm{I}}\right)$ obtained from the instability tests and the fitting curves are plotted in Fig. 8. A power function was selected to fit the data points and the parameter values are shown in this figure. The fitting curves are down convex; thus, the sensitivity of $\eta_{\mathrm{I}}$ to $e_{\mathrm{I}}$ may be relatively strong when $e_{\mathrm{I}}$ is small and may become weaker with an increase in $e_{\mathrm{I}}$, which is consistent with the test results for sand conducted by Chu et al. (2003). By comparing the test results of groups A and B, it was found that the instability stress ratios of the specimens in group A were generally lower than those of the specimens in group B. This is understandable in view of the beneficial role of reinforcement components in the constraining large deformation, as discussed in the previous section entitled 'Results of the instability tests with a CSD stage'.

\section{DISCUSSION: CAUSE OF WASTE INSTABILITY CONSIDERING REINFORCEMENT EFFECTS}

It is generally believed that reinforcement components play an important role to induce special mechanical behaviours of waste. In this section, some factors leading to waste instability are discussed from the perspective of reinforcement effects.

The effects of reinforcement components are closely related to the effectiveness of anchorage. Effective mean stress is an important factor to influence the effectiveness of anchorage (Zekkos, 2005; Machado et al., 2008). On the one hand, $p^{\prime}$ continuously decreased in CSD tests, which may lead to anchoring deficiency. Then, the effect of reinforcements in waste may be weakened. On the other hand, with the decrease in $p^{\prime}$, the stress ratio $q / p^{\prime}$ continuously increased, leading to an increase in the load sustained by reinforcements, which made the situation worse. Therefore, both aspects meant that the reinforcement components in waste cannot play an effective role, and thus contributed to the instability or even collapse of waste specimens. 


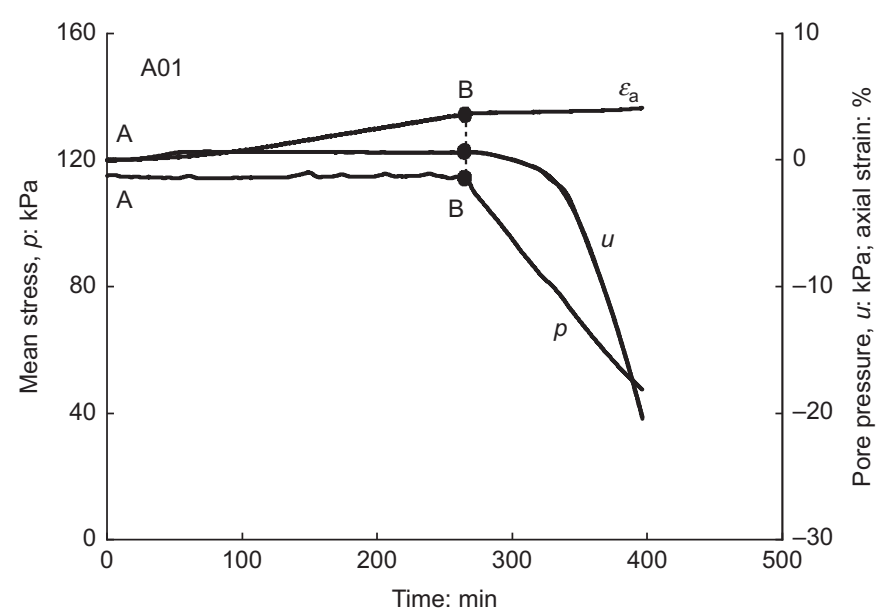

(a)

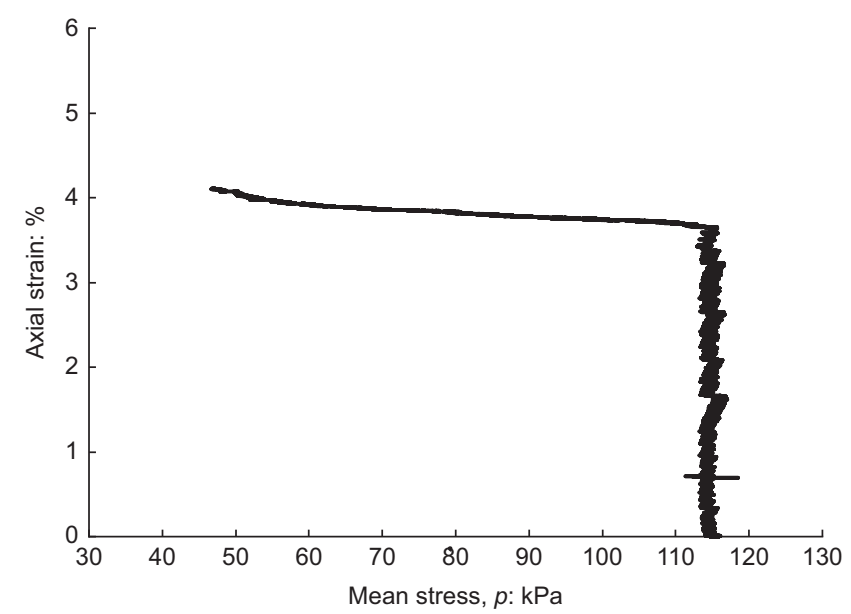

(b)

Fig. 6. Results of test A01: (a) mean stress, pore pressure and axial strain plotted against time curves and (b) axial strain plotted against mean stress curve

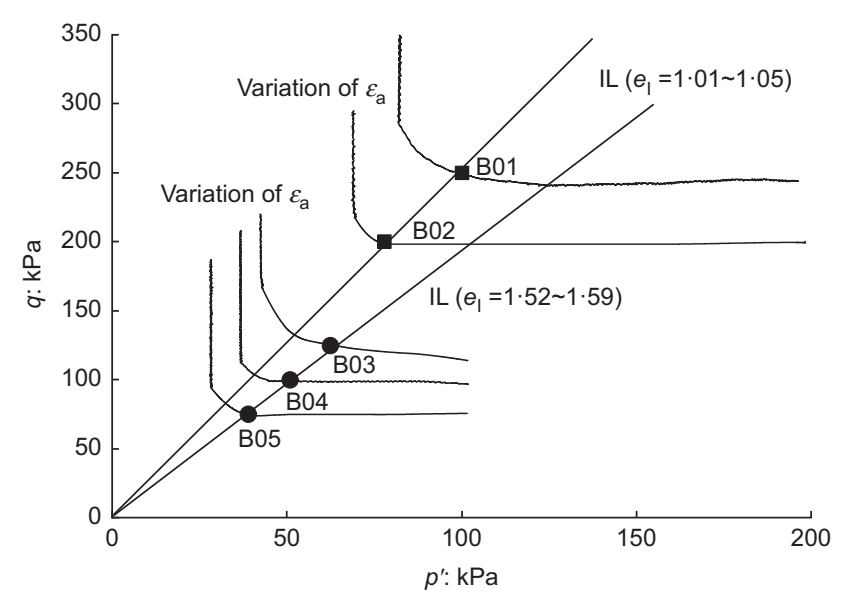

Fig. 7. Instability lines (IL) of the tested waste of group B

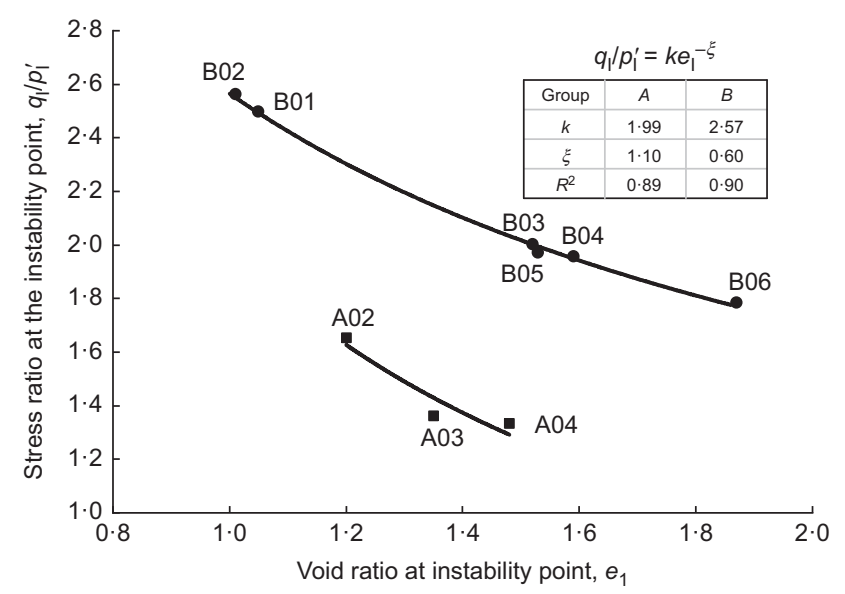

Fig. 8. Relationship of the stress ratio and the void ratio at the instability point

However, the fact that waste specimens did not exhibit pre-failure softening in CU tests cannot be completely explained when only considering stress paths, since the increase in $q / p^{\prime}$ and decrease in $p^{\prime}$ also existed. In the present authors' opinion, the reasons why waste specimens became unstable in CSD tests but exhibited hardening behaviours in $\mathrm{CU}$ tests need to be discussed by considering the effects of deformation characteristics on the mobilisation of reinforcement effects.

Essentially, reinforcement components in waste play an effective role by yielding tensile deformation. Thus, the mobilisation degree of reinforcement effects is related to the plastic deformation of waste. In $\mathrm{CU}$ tests, the waste specimens were always in a plastic state; thus, plastic deformation continuously developed. This situation was relatively conducive to the plastic deformation of the reinforcement and the mobilisation of reinforcement effects. As long as the reinforcement effects can be mobilised sufficiently to withstand the external loads, waste specimens can exhibit continuously hardening behaviours and this, in fact, is what occurred. Nevertheless, the situations in the CSD tests were totally different. From point B to I, waste specimens were in an elastic state and plastic deformation did not develop in any obvious way. In this process, the reinforcement effects cannot be further mobilised. Therefore, when the specimens entered a plastic state after point $I$, the mobilisation degree of the reinforcement effects could only match the stress ratio at point B. Then, under a stress ratio obviously higher than point $\mathrm{B}$, it was difficult for the reinforcement components to inhibit the instability of waste specimens after point I.

Under the condition of continuous development of plastic deformation of waste specimens, the different effects of volume contraction and dilation of waste on reinforcement effects should also be noted. When the waste volume contracts or exhibits a contraction tendency in the plastic state - for example, in $\mathrm{CU}$ and other conventional compression triaxial tests - the particles will move close to each other or have a similar tendency. Then, the interaction effects between the reinforcement components and other waste particles may be strengthened, which is beneficial to the mobilisation of reinforcement effects and thus contributes to the continuous hardening behaviour. However, the waste specimens exhibited plastic dilation in CSD tests. In this situation, the reinforcement components may not effectively restrain the deformation of other components, which was detrimental for the mobilisation of reinforcement effects. Therefore, volume dilation may be regarded as an important factor to aggravate the instability of waste specimens in CSD tests.

\section{ENGINEERING SIGNIFICANCE OF WASTE INSTABILITY}

The safety of the waste slope generally needs to be addressed in two situations. The first situation is when the 


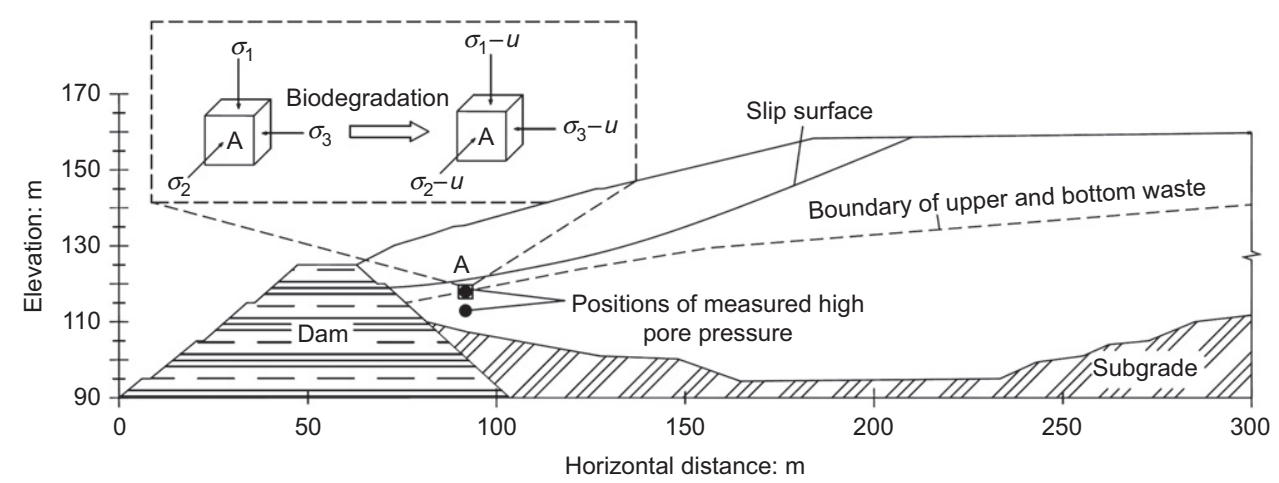

Fig. 9. A case of waste sliding that may be related to waste instability (after Ma et al., 2019)

waste mass is in the dumping operation period. In the dumping process, the waste usually causes an increase in the external load; thus, its mechanical responses are closer to those in conventional triaxial compression tests. The second situation is when the waste mass has been dumped, but high pore pressure is generated in the waste, for many reasons. In this situation, the actual stress path of waste may be similar to the constant $q$ path and waste instability may occur. The engineering significance of waste instability mainly relies on the slope safety evaluation in the second situation.

A sliding case caused by high pore pressure is given here. In November 2017, waste sliding occurred in the Xingfeng Landfill, Guangzhou, China (Ma et al., 2019). As illustrated in Fig. 9, the waste mass was composed of relatively old waste (age $>2.5$ years) in the bottom layer and relatively fresh waste (age $=1 \cdot 0-1.5$ years) in the upper layer. With respect to the sliding, two facts should be noted. First, the waste slope was stable at the end of dumping of the upper layer, but slid nearly a year later. When the sliding did occur, there was only a small-scale dumping operation taking place at the top of the slope. This indicates that the sliding had little to do with the dumping operation. Second, a high pore pressure zone in the waste mass close to the slip surface was investigated by using drilling and electrical resistivity tomography and the high pore pressure in it was approximately $50 \mathrm{kPa}$ larger than the hydrostatic pressure at the same depth. As discussed by Ma et al. (2019), the effects of gas pressure in the waste in the high-pore-pressure zone can be equivalent to water pressure; thus, the stress state variation of a waste element in a high-pore-pressure zone during biodegradation can be illustrated by Fig. 9, which was very similar to the constant $q$ stage of the CSD tests. Judging from the above facts, the instability may be an important factor to facilitate the waste sliding. As mentioned in the earlier section 'Test apparatus and specimens', it should be noted that the effective stress needs to be modified under high pore pressure if waste has high particle compressibility.

In addition to above case, there were also some cases of waste sliding that may be related to the increase in pore pressure and the waste instability according to the field reconnaissance and back-analysis of other researchers (e.g. Giraldo et al., 2002; Merry et al., 2005; Athanasopoulos et al., 2013).

Based on the test results in this study, some suggested measures can be taken to reduce the risk of sliding caused by waste instability. First, the density of waste should be improved by effective compaction during dumping. As shown in Fig. 8, a lower void ratio corresponds to a higher instability stress ratio, meaning that waste with a higher density has a higher resistance to instability. Second, the excessive pore pressure accumulated in the waste mass should be eliminated as much as possible by an effective liquid-gas collection system.
However, in the landfills of developing countries, which have a high food waste content, because the yields of leachate and landfill gas during the biodegradation are very high, effective collection is relatively difficult to perform. To solve this problem, Zhan et al. (2017) proposed a three-dimensional drainage system, which has been used successfully in many landfills. Third, except for insufficient liquid-gas collection during biodegradation, factors that can increase the pore pressure in a short time, such as rainfall infiltration induced by low-quality cover, should also be noted. Especially at the dumping surface, effective measures of temporary cover and drainage are needed to avoid the rapid increase in pore pressure and the instability of fresh waste.

\section{CONCLUSIONS}

The following conclusions can be drawn based on the present study.

(a) In CU tests, waste specimens did not exhibit pre-failure softening like loose sand. Through modification by considering particle compressibility, the stress ratio decreased while the hardening tendencies were maintained.

(b) The instability of the tested waste occurred in the instability tests with a CSD stage, whereas it did not occur in the instability test with a CSU stage. The instability behaviours of the waste included an increase in the axial strain, dilation of the specimen volume and softening.

(c) For the waste specimens with similar void ratios, the instability points were located around an IL in the meridian plane. The slope of the ILs decreased with an increase in the void ratio. The stress ratios at the instability points of the tests of group B were generally larger than those of the tests of group A, indicating that aged waste may have higher resistance to instability.

(d) From the perspective of reinforcement effects, the stress paths and deformation characteristics of waste specimens in CSD tests may be the factors that induced their unstable behaviours.

(e) Waste instability should be considered in the safety evaluation of waste slopes when high pore pressure is generated, because waste may go through a stress path similar to a constant $q$ path in this situation.

Compared with the artificial waste used in this study, the components of natural waste are much more complicated, and the particle sizes of some components are much larger. Thus, strictly speaking, the conclusion obtained in this study cannot be generalised directly to engineering applications 
owing to the limitations of the waste materials used. In future research, considering the engineering applications, more elements and large-scale tests of waste instability using natural waste are suggested.

\section{ACKNOWLEDGEMENT}

The authors would like to acknowledge the financial support from the National Key R\&D Program of China by grant number 2019YFC1806000.

\section{NOTATION}

$$
\begin{aligned}
C & \text { overall compressibility }\left(\mathrm{MPa}^{-1}\right) \\
C_{\mathrm{s}} & \text { particle compressibility }\left(\mathrm{MPa}^{-1}\right) \\
\mathrm{d} \varepsilon_{\mathrm{a}} / \mathrm{d} t & \text { rate of axial strain } \\
e & \text { void ratio } \\
e_{\mathrm{c}} & \text { void ratio after consolidation } \\
e_{\mathrm{I}} & \text { void ratio at the instability point } \\
k \text { and } \xi & \text { parameters describing the relation between } \eta_{\mathrm{I}} \text { and } e_{\mathrm{I}} \\
p \text { and } p^{\prime} & \text { mean and effective mean stress }(\mathrm{kPa}) \\
p_{\mathrm{I}}^{\prime} & \text { effective mean stress at the instability point }(\mathrm{kPa}) \\
q & \text { deviatoric stress }(\mathrm{kPa}) \\
q_{\mathrm{I}} & \text { deviatoric stress at the instability point }(\mathrm{kPa}) \\
\Delta u & \text { pore pressure and pore pressure change }(\mathrm{kPa}) \\
V \text { and } \Delta V & \text { overall volume and overall volume change }\left(\mathrm{cm}^{3}\right) \\
V_{\mathrm{p}} \text { and } \Delta V_{\mathrm{p}} & \text { particle volume and particle volume change }\left(\mathrm{cm}^{3}\right) \\
\Delta p^{\prime} & \text { effective mean stress change }(\mathrm{kPa}) \\
\lambda & \text { parameter describing the relation between } C\left(\mathrm{or} C_{\mathrm{s}}\right) \\
& \text { and } p^{\prime} \\
\varepsilon_{\mathrm{a}} & \text { axial strain } \\
\varepsilon_{\mathrm{V}} & \text { volume strain } \\
\eta & \text { stress ratio } \\
\eta_{\mathrm{I}} & \text { stress ratio at the instability point } \\
\sigma_{1}^{\prime} & \text { effective vertical stress in the triaxial condition }(\mathrm{kPa}) \\
\sigma_{3}^{\prime} & \text { effective confining stress in the triaxial condition } \\
& \text { (kPa) }
\end{aligned}
$$

\section{REFERENCES}

Anderson, S. A. \& Riemer, M. F. (1995). Collapse of saturated soil due to reduction in confinement. J. Geotech. Engng 121, No. 2, 216-220, https://doi.org/10.1061/(ASCE)0733-9410(1995)121:2 (216).

Athanasopoulos, G., Vlachakis, V., Zekkos, D. \& Spiliotopoulos, G. (2013). The December 29th 2010 Xerolakka municipal solid waste landfill failure. In Proceedings of 18th international conference on soil mechanics and geotechnical engineering: challenges and innovations in geotechnics (eds P. Delage, J. Desrues, R. Frank, A. Puech and F. Schlosser), vol. 1, pp. 309-312. Paris, France: Presses des Ponts.

Blight, G. (2008). Slope failures in municipal solid waste dumps and landfills: a review. Waste Manage. Res. 26, No. 5, 448-463, https://doi.org/10.1177/0734242x07087975.

Bray, J. D., Zekkos, D., Kavazanjian, E., Athanasopoulos, G. A. \& Riemer, M. F. (2009). Shear strength of municipal solid waste. J. Geotech. Geoenviron. Engng 135, No. 6, 709-722, https://doi.org/10.1061/(ASCE)GT.1943-5606.0000063.

Chu, J. \& Leong, W. (2001). Pre-failure strain softening and pre-failure instability of sand: a comparative study. Géotechnique 51, No. 4, 311-321, https://doi.org/10.1680/geot. 51.4.311.39402.

Chu, J., Lo, S. R. \& Lee, I. K. (1992). Strain-softening behavior of granular soil in strain-path testing. J. Geotech. Engng 118, No. 2, 191-208, https://doi.org/10.1061/(ASCE)0733-9410 (1992)118:2(191).

Chu, J., Leroueil, S. \& Leong, W. K. (2003). Unstable behaviour of sand and its implication for slope instability. Can. Geotech. J. 40, No. 5, 873-885, https://doi.org/10.1139/t03-039.

Chu, J., Wanatowski, D., Leong, W. K., Loke, W. L. \& He, J. (2015). Instability of dilative sand. Geotech. Res. 2, No. 1, 35-48, https://doi.org/10.1680/gr.14.00015.

Dong, Q. Y., Xu, C. J., Cai, Y. Q., Juang, H., Wang, J. \& Yang, Z. X. (2017). Drained instability in loose granular material.
Int. J. Geomech. 16, No. 2, 04015043, http://10.1061/(ASCE) GM.1943-5622.0000524.

Dixon, N. \& Jones, D. R. V. (2005). Engineering properties of municipal solid waste. Geotext. Geomembr. 23, No. 3, 205-233, http:// https://doi.org/10.1016/j.geotexmem.2004.11.002.

Feng, S. J. (2005). Soil and dynamic strength properties of municipal solid waste and stability analysis of landfill. $\mathrm{PhD}$ thesis, Zhejiang University, Hangzhou, China (in Chinese).

Feng, S. J., Chen, Z. W., Chen, H. X., Zheng, Q. T. \& Liu, R. (2018). Slope stability of landfills considering leachate recirculation using vertical wells. Engng Geol. 241, 76-85, https://doi.org/ 10.1016/j.enggeo.2018.05.013.

Giraldo, E., Caicedo, B., Yamin, L. \& Soler, N. (2002). The landslide of Dona Juana landfill in Bogota. A case study. In Proceedings of the fourth international congress on environmental geotechnics (4th ICEG) (eds L. G. Mello and M. Almeida), pp. 171- 175. Rotterdam, the Netherlands: Balkema.

Karimpour-Fard, M., Machado, S. L., Shariatmadari, N. \& Noorzad, A. (2011). A laboratory study on the MSW mechanical behaviour in triaxial apparatus. Waste Manage. 31, No. 8, 1807-1819, https://doi.org/10.1016/j.wasman.2011. 03.011.

Ke, H., Chen, Y. M., Dong, D., Guo, C. \& Feng, S. J. (2019). Non-linear elastic model for MSW considering dilatancy effect. Environ. Geotech. 6, No. 3, 125-136, https://doi.org/10. 1680/jenge. 16.00015 .

Koerner, R. M. \& Soong, T. Y. (2000). Stability assessment of ten large landfill failures. In Proceedings of advances in transportation and geoenvironmental systems using geosynthetics (eds J. C. Zornberg and B. R. Christopher), Geotechnical Special Publication no. 103, pp. 1-38, https://doi.org/10.1061/40515 (291)1. Reston, VA, USA: American Society of Civil Engineers.

Lade, P. V. (1993). Initiation of static instability in the submarine Nerlerk berm. Can. Geotech. J. 30, No. 6, 895-904, https://doi. org/10.1139/t93-088.

Lade, P. V. \& Pradel, D. (1990). Instability and plastic flow of soils. I: experimental observations. J. Engng Mech. 116, No. 11, 2532-2550, https://doi.org/10.1061/(ASCE)0733-9399(1990) 116:11(2532).

Lade, P. V., Nelson, R. B. \& Ito, Y. M. (1988). Instability of granular materials with nonassociated flow. J. Engng Mech. 114, No. 12, 2173-2191, https://doi.org/10.1061/(ASCE)0733-9399(1988) 114:12(2173).

Ma, P. C., Ke, H., Lan, J. W., Chen, Y. M. \& He, H. J. (2019). Field measurement of pore pressures and liquid-gas distribution using drilling and ERT in a high food waste content MSW landfill in Guangzhou, China. Engng Geol. 250, 21-33, https://doi.org/ 10.1016/j.enggeo.2019.01.004.

Machado, S. L., Carvalho, M. F. \& Vilar, O. M. (2002). Constitutive model for municipal solid waste. J. Geotech. Geoenviron. Engng 128, No. 11, 940-951, https://doi.org/10.1061/(ASCE)1090-0241 (2002)128:11(940).

Machado, S. L., Vilar, O. M. \& Carvalho, M. (2008). Constitutive model for long term municipal solid waste mechanical behavior. Comput. Geotech. 35, No. 5, 775-790, https://doi.org/10.1016/ j.compgeo.2007.11.008.

Machado, S. L., Vilar, O. M., Carvalho, M. F. \& Karimpour-fard, M. (2017). A constitutive framework to model the undrained loading of municipal solid waste. Comput. Geotech. 85, 207-219, https://doi.org/10.1016/j.compgeo.2016.12.002.

Merry, S. M., Kavazanjian, E. \& Fritz, W. U. (2005). Reconnaissance of the 10 July 2000, Payatas landfill failure. J. Perform. Constr. Facil. 19, No. 2, 100-107, https://doi.org/ 10.1061/(ASCE)0887-3828(2005)19:2(100).

Powrie, W., Beaven, R. P. \& Harkness, R .M. (1999). Applicability of soil mechanics principles to household waste. In Sardinia 99: seventh international waste management and landfill symposium (eds T. H. Christensen and R. Cossu), pp. 429-436. Cagliari, Italy: CISA, Environmental Sanitary Engineering Centre.

Shariatmadari, N., Machado, S. L., Noorzad, A. \& Karimpour-Fard, M. (2009). Municipal solid waste effective stress analysis. Waste Manage. 29, No. 2, 2918-2930, https://doi. org/10.1016/j.wasman.2009.07.009.

Skempton, A. W. (1960). Effective stress in soils, concrete and rocks. In Proceedings of the conference on pore pressure and suction in soils, pp. 4-16. London, UK: Butterworth. 
Turner, B. A. \& Pidgeon, N. F. (1997). Man-made disasters, 2nd edn. London, UK: Butterworth-Heinemann.

Zekkos, D. P. (2005). Evaluation of static and dynamic properties of municipal solid-waste. PhD thesis, University of California, Berkeley, CA, USA.

Zhan, L. T., Xu, H., Chen, Y. M., Lan, J. W., Lin, W. A. \& Xu, X. B. (2017). Biochemical, hydrological and mechanical behaviors of high food waste content MSW landfill: liquid-gas interactions observed from a large-scale experiment. Waste Manage. 68 , 307-318, https://doi.org/10.1016/j.wasman.2017.06.023.

Zhan, L. T., Zhang, Z., Chen, Y. M., Chen, R., Zhang, S., Liu, J. \& Li, A. G. (2018). The 2015 Shenzhen catastrophic landslide in a construction waste dump: reconstitution of dump structure and failure mechanisms via geotechnical investigations. Engng Geol. 238, 15-26, https://doi.org/10.1016/j. enggeo.2018.02.019. 